University of Nebraska - Lincoln

DigitalCommons@University of Nebraska - Lincoln

May 1988

\title{
A Sociobiological Perspective on the Development of Human Reproductive Strategies
}

\author{
Patricia Draper \\ University of Nebraska, Lincoln, pdraper1@unl.edu \\ Henry Harpending \\ University of Utah, henry.harpending@anthro.utah.edu
}

Follow this and additional works at: https://digitalcommons.unl.edu/anthropologyfacpub

Part of the Anthropology Commons

Draper, Patricia and Harpending, Henry, "A Sociobiological Perspective on the Development of Human Reproductive Strategies" (1988). Anthropology Faculty Publications. 11.

https://digitalcommons.unl.edu/anthropologyfacpub/11

This Article is brought to you for free and open access by the Anthropology, Department of at DigitalCommons@University of Nebraska - Lincoln. It has been accepted for inclusion in Anthropology Faculty Publications by an authorized administrator of DigitalCommons@University of Nebraska - Lincoln. 
Published in Sociobiological Perspectives on Human Development, ed. Kevin B. MacDonald. New York: Springer Verlag, 1988, as chapter 12, pp. 340-372. Copyright (C) 1988 Springer-Verlag. Used by permission.

\title{
A Sociobiological Perspective on the Development of Human Reproductive Strategies
}

\author{
Patricia Draper and Henry Harpending
}

\section{Overview}

A current view in the human sciences emphasizes an understanding of the individual as a representative of a past history of selection for survivorship and reproduction. All of us are descendants of individuals who lived long enough to produce reproductive offspring. Our current generation represents the variable mating success of our ascendants. Some of our grandparents and great grandparents had many offspring, others had only one or two. At each generation there are new opportunities to expand and to contract the genetic contribution of particular individuals to future generations. Since evolution favors those (1) who survive and (2) who are most successful at reproduction, we expect Darwinian theory to be most immediately helpful for comprehending our survivorship, mating, and parenting, while it may be less immediately applicable to domains like religion that are less intimately tied to fitness. In the case of humans, for whom learning plays a central role in differentiating reproductive success from failure, the social circumstances and social lessons we experience play a substantial role in influencing our reproductive behavior, the number of offspring we have, and the manner in which we rear those offspring. Learning also contributes to the social niche we occupy during the lifespan. Attention therefore is increasingly focused by sociobiologists on the evolution of human learning. While learning is "intangible" in a practical sense, it becomes analytically and conceptually more corporeal when we consider the fact that what individuals learn contributes deterministically to reproduction and differences among individuals in reproduction. In this chapter we wish to consider the relationships among human reproductive behavior, learning experience, and the social institutions of the society in which the individual matures. Our approach differs from more usual social science analysis in that we do not assume temporal and functional interdependence among these variables. We are as interested in why there are functional interdependencies as in the fact and the shape of those that do exist. 
Humans show a great deal of variability in their reproductive behavior, including types of sexual activity, types of ties between males and females, and ways of arranging for the rearing of offspring. We will consider three principal topics: (1) Father absence versus father presence, contrasting children who are reared in a family system in which there is a closely involved and economically contributing father in contrast to a family system in which women rear their children in cooperation with other women (usually kin) and without consistent help from a man who is father to children. (2) Peer rearing versus parent rearing, concerning who does the primary work of rearing children-whether biological parents themselves and in a proximate sense provide for the care of their own children or whether parental surrogates do the major child tending work under some form of distal parental supervision. (3) Pair-bonding between parents versus individual strategies that do not include reciprocation with a mate, with a view toward understanding several psychiatric "disorders" as manifestations of more general evolved propensities against cooperation.

In the first two cases we discuss the consequences which being reared under one or the other of these conditions can have for the individual's reproductive strategy. For simplicity we portray the conditions as dichotomous alternatives but we recognize that in actual life individual experience can vary along a continuum from one to the other. There are data on these topics, and evolutionary theory can help us understand these patterns in a way that takes account both of environmental differences among groups and the evolved characteristics of our species.

The evidence about why some adults seem to prefer to bond with one individual of the opposite sex while others mate in quite different contexts is quite sketchy. We will discuss characteristics of sociopaths and hysterics, individuals with clusters of traits identified by psychiatrists and usually interpreted as victims of mental illnesses. We will point out that these trait clusters seem to make good sense when considered in the light of the evolutionary theory of reproductive strategies, even though there is no good evidence of learning or of effects of rearing environment on their development.

Our view of learning is that humans have been selected to be differentially sensitive to certain cues in their immediate early childhood environment (Bowlby 1969, 1973; Lumsden \& Wilson, 1981; MacDonald, 1984). It is as if human young acquire early socialization with their antennae tuned to detect certain attributes in their environment, especially the role played by mother's mate and the mother's attitude to her mate(s), and the role of parents as opposed to nonparental surrogates in providing proximate care in early childhood. These are examples of contextual variables which influence learning tracks in early childhood (MacDonald, this vol., Chap. 1) and which can be understood in the context of our evolutionary past. A fuller account of the hypothe- 
ses and the supporting assumptions and evidence is provided later in this chapter.

We also consider reciprocity and cooperation in everyday interactions among individuals. It is probably not true that the most reproductively successful people in the past were those that were the most cooperative and altruistic, because others could have taken advantage of model citizens. Yet reciprocity is the foundation of human social life: we expect that there will be a rich array of learning biases and manipulative abilities in our species in this domain. Some humans seem to be more likely to cheat than others, but it is not clearly known whether the propensity is a product of genes or of the learning environment. Further, human males and females who cheat do it in sensibly different ways. We discuss this more below in the section on "Criminality and Hysteria." Whether learned or not, the "cheating model of sociopathy and hysteria" is a good model of the potential for evolutionary reasoning to broaden our understanding of behavioral diversity in our own species, and we believe it worth covering in some detail even in the absence of good information about mechanisms.

\section{Introduction}

Sociobiology has had a difficult time becoming established in the social sciences because of entrenched ideas that human adaptation is primarily by means of culture and that culture is learned. Some call it an extrasomatic form of adaptation. Whereas it is relatively easy to convince social scientists of the inherent utility of Darwinian logic as applied to nonhuman animals, it is not so easy when it comes to humans. Humans, after all, rely on learning for everything that is significant about human adaptation. Furthermore, humans differ markedly from each other in customs that enable group survival, but perhaps even more in customs that seem to have little relationship to group survival.

For example, human economic practices are highly variable-they include simple foraging by people living in small kin groups, as well as simple food production systems at higher densities, and may involve more complex leadership roles such as chiefs and ritual leaders. Peasant social systems with high degrees of social stratification are more familiar to contemporary people. Still more exotic are the economic and political forms of postindustrial society. Marriage and family forms are heterogeneous across societies of varying degrees of complexity as are fertility regimes, which vary from, at, or near replacement levels (Western societies) to fertility rates which produce population doubling in 20 years (modern Kenya and Afghanistan). 
Given this diversity, how can it be argued that humans like other animals have been biologically programmed? Many draw what seems the obvious conclusion: humans differ profoundly from nonhuman animals. Tissue and bone may be homologous structures but developments in the human evolutionary line have led to qualitative differences in the organization and potential of our species. We are unique, particularly with respect to the morphology of the greatly enlarged brain and in the critical role played by postnatal learning in enabling our adaptation to the environment. There are several things wrong with this approach.

\section{Learning, Adaptation, Variability}

1. Humans are not unique in the animal kingdom in the role played by individual learning in explaining individual survival and differences among individuals in survival and reproductive success (Durham, 1976). Research among mammalian social species and in particular the higher primates (monkeys and apes) reveals the critical role of postnatal learning in individual development. We also understand the degree to which individuals in nonhuman animal populations vary among themselves in behavioral strategies both in dealing with conspecifics and in dealing with other organisms and features of their environment. Long-term research on a variety of social mammalian species that employs techniques of behavioral observation has revealed that each organism may play a specialized social role contingent upon his or her own life history, availability of resources, relations with other members of the social group, and other factors (Altmann, 1980; Dublin, 1983; Silk \& Boyd, 1983; Wrangham, 1980).

\section{Species Context of Learning}

2. We now realize that the individual organism does not come equipped with a generalized capacity to learn "anything" in the way of responses to cues that are coupled with consistent rewards and punishments. Instead, there is a growing understanding of the fact that natural selection has shaped the central nervous system to promote the "ease of learning" of certain responses which themselves are conducive to the survival and ultimately the reproduction of the individual.

The easiest example of so-called learning propensities has occurred to anyone who has had a child and, at any time, a kitten. Kittens learn about cat litter after being placed there once-they find it very easy to learn. Humans, on most grounds better learners than cats, have no such easy time with the human equivalent of cat litter.

The psychologist John Garcia is known for bringing the subject of evolved ease of learning into experimental psychology. In experiments 
with rats, he showed that they very quickly and easily learned to avoid a certain drink if they were (artificially) made nauseous after consuming it. If they were punished instead with electric shock in association with eating they did not learn to avoid the food. Similarly, the punishment of electric shock taught them easily to respond to lights, but nausea did not condition the response to lights. It seems obvious, in retrospect, that a well-designed rat would associate foods with nausea and external stimuli with external pain, but it was not so obvious to many psychologists (Garcia, McGown, \& Green, 1972; Konner, 1982). The ease with which we learn idiosyncratic food aversions after their accidental association with nausea or digestive disorder is called the Garcia effect. The general principle is that the Garcia effect is an example of a learning rule.

Another example of learning predispositions which reflect preadaptation to an evolutionarily expected environment is the effect which the human face (or a schematic representation) has in capturing the attention of newborn infants (Ahrens, 1954; cited in Freedman, 1974). The face is apparently a "natural cue" indicating that neonates are born with some neurological structures in place which determine that some unconditioned cues are inherently more rewarding than others.

\section{Renewed Interest In Human Similarities}

3. Human cultural variability no longer seems as extreme as it once did. Instead, we are becoming less impressed with differences of complexity, density, and technology in different human populations and more aware of how humans are basically similar, at least with regard to fundamental behaviors which are central to Darwinian fitness. This is not to diminish the very substantial and interesting differences which humans exhibit with respect to practices regarding competition, sexuality, mating, and parenthood. However, as we understand more about the factors which condition the variability in social and reproductive behavior in nonhuman animal species, we are led to new inquiries about humans.

An instructive example comes from studies of species which show facultative shifts in mating behaviors. The changes away from a baseline of practices common to a population in a particular region may be occasioned by such changes as availability of resources, predator density, density of conspecifics, etc. Under resource-scarce conditions, wolves form heterosexual packs of several reproductively mature individuals as well as subadults (Packer \& Pusey, 1984). However, only one pair typically reproduces. Other subordinates do not engage in sexual behavior. On the other hand, when conditions permit pack dispersal, these same subordinates form pairs and rear offspring. Some individuals in a bird population normally characterized by monogamy 
will shift over to polygynous unions when foodstuffs become unexpectedly abundant (Emien \& Oring, 1977; Verner, 1964). In this case males compete for territorial control of rich areas and several females accept the territory-controlling male as mate, forgoing his parental help in lieu of the improved foraging conferred by locating their nests in his territory. Similar examples are abundant in the animal literature. (See Weatherhead \& Robinson, 1979).

As can be seen from these examples, with an improved understanding of the complexity and subtlety of nonhuman animal adaptation it is possible to understand human behavioral variability as not totally different in kind (Barkow, 1980; Chagnon \& Irons, 1979; Kurland, 1979; van den Berghe, 1980). In the context of cross-species comparison, human sciences have acquired another dimension, the evolutionary one. What kind of biopsychological creature are we? What past environments have our phylogenetic ancestors passed through which have created selective funnels for the transmission of various traits having to do with physiology, morphology and behavioral response?

Scholars who wish to apply evolutionary logic to human behavior operate at an inherent disadvantage. We are a long-lived species, which means that it is next to impossible to determine in the present time what may be the long-term consequences of a particular behavior by an individual or a group. In addition, our knowledge is limited regarding the types of selective pressures our ancestors encountered. We have the contemporary phenomenon of several billion humans pursuing a variety of careers and goals, but how is sense to be made of this? We need an informed evolutionary biology for the social sciences, something analogous to the baleen used by whales in separating the tiny but nutritious krill from thousands of gallons of seawater.

\section{Learning Biases}

We think that a road map to clarity will be built from a new theory of learning. There are many ways to classify learning, and there are concepts like "reflex" that some would call learning and some not. We want to mention here a way of thinking about learning and the relationship of learning to evolution that has been stated most clearly by Boyd and Richerson (1985). Learning mechanisms can be distinguished according to whether or not they are cheap and easy or expensive and hard, as well as according to whether they are biased or unbiased. Then, our task becomes understanding what kind of learning mechanism will evolve under what circumstances, when testing this understanding against empirical data about human learning. This is the so-called deductive approach to science, and it is the one that has historically worked in most fields. The inductive approach would be to try to classify learning according to our scholarly investigation of 
its manifestations without direction from a preexistent theory. Such a classification might not bear a relationship to the (evolutionary) mechanisms that generated our learning capacities.

Easy learning, or social learning, is inexpensive passive absorption of what is being observed or taught. Perhaps the best example is that of language learning in childhood: children typically learn to speak without being taught and they learn a close approximation to what they hear. Contrast this inexpensive, painless learning with, say, learning multiplication tables or calculus. It is hard to avoid the conclusion that we are designed to learn language and that we learn it by a rather special mechanism that does not generalize easily to other domains.

Why doesn't this easy learning generalize? For an answer, we have to consider the social and natural environment in which we evolved and consider the costs or disadvantages of easy learning. One obvious disadvantage of easy learning is that, if the environment changes, we might learn outdated information and not do as well as another individual who learned up-to-date information, albeit with greater cost.

For example, a learning rule that directed a young male to learn, as easily as he learns language, the subsistence behaviors of his father, would be strongly disfavored in the event of a change in the subsistence base of the group. A committed hunter would do poorly if the only food available were fish. It is probably always advantageous to speak the language of the group, but it may often be advantageous to prefer to learn subsistence practices different from those of others, since there would be less competition for them.

A second more subtle disadvantage of easy learning is that we might be taught information that was ultimately contrary to our own best interests by less than benevolent conspecifics. An easy learner would be too gullible for his or her own (reproductive) interests. Since we reproduce sexually, our offspring are not genetically identical with us, they have different (reproductive) self-interests, and a child too readily indoctrinated by his or her parents would not do as well, over the long term, as a child who was less gullible. For example, optimized parents would try to teach their children to treat other siblings better than the level of sibling altruism optimum for the child (Trivers, 1974).

The opposite of social learning or easy learning is expensive, hard learning that requires substantial amounts of time, energy, or risk. The advantages and disadvantages mirror those of easy learning discussed above-hard learning is more careful, discriminating, and less prone to error. It seems that hard learning is the natural state for learning for many human activities, in that it seems to be hard for our species to learn evolutionarily novel things like algebra or assembly language.

Biased learning refers to the learner's preferences and propensities filtering the material presented and available for learning. This 
is broadly synonymous with prepared learning. For example, in the face of very similar classroom experiences males seem to learn certain kinds of spatial tasks more readily than do females, while females outperform males in certain linguistic domains. These learning biases, further, are affected by physiological processes, especially those apparent during early development (Ehrhardt \& Baker, 1974). There is probably much to be learned about biased learning in the domain of moral learning and the learning and development of social skills in general. (See this vol., Chaps. $4 \& 5$ ). Many humans are taught to be much more altruistic, honest, and moral than they actually are as evidenced by their behavior. Unfortunately, much of our knowledge in this domain is about what people say on questionnaires and in interviews rather than about what they actually do in their everyday lives.

In terms of the original goals that we discussed, we now propose that certain classes of reproductive behavior are the result of interaction between learning biases and particular experiential and institutional configurations experienced by individuals.

\section{Father Absence}

An advantage of sociobiological analysis is that it represents a higher order or more inclusive framework within which the data of the social sciences may be reexamined. By asking the question "What fitness gains may return to individuals who behave one way as opposed to another?" one gains a new kind of leverage in understanding why certain learning experiences seem to produce a given outcome. We believe that the diversity of outcomes of father absence and presence makes a great deal of sense when it is considered in the framework of sensitive-period learning of reproductive strategies (Draper \& Harpending, 1983).

We suggest that natural selection has favored a learning bias in children for the acquisition of reproductive style. The activation of this learning bias depends on contextual cues in the environment, and these cues are associated with the mother's pair-bond status. We do not know nor have we theoretical reasons for predicting what precisely is the mechanism which triggers the learning track "chosen" by the child. Further research particularly of a type for which social learning psychologists are well suited will be necessary. (See Blain \& Barkow, this vol., Chap. 13.) The rationale behind the suggestion of learning bias for reproductive strategy is as follows: Humans have multiplied rapidly since the end of the Pleistocene and have spread in the last 40,000 years into a wide range of physical environments. In the process of this geographic dispersal humans have generated a wide diversity of social environments which have changed rapidly in time and in space. The social environments themselves have evolved, perhaps in response to the nature of 
essential resources and the availability of them. As a result, any set of human genetic material has been exposed to a diversity of social environments over the most recent tens of thousands of years, and certainly the fitness of individuals in many human societies is more dependent upon social skills than upon skills in manipulating the extrasocial environment. This unstable diversity of social environments is precisely the context where phenotypic plasticity would enjoy the greatest advantage over any fixed strategy (Cavalli-Sforza, 1974).

If prolonged practice and attention is required for the successful function of some activity in adulthood, and if at the same time there is general environmental variability changing through time, but changing slowly compared to the scale of an individual lifetime, then the optimum mode of adaptation may be to establish early in development a learning track which guides later learning and practice. Humans are unusual in the extent to which their behavior remains open, i.e., capable of being channeled through learning. It seems that human mating behavior, while clearly constrained fairly sharply by factors not susceptible to modification by learning, is "open" within a range, so that an individual can "choose" a reproductive style which is appropriate in the metric of fitness to aspects of the social environment perceived in early life.

\section{The Role Of Males}

In considering the diversity of human cultures, we have divided them into those that are, in our terms, father-absent and those that are father-present. This dichotomy is, of course, not the only way to classify cultures, but it is a classification that proceeds from a prior theory about human behavior. Our father-present societies correspond to what Whiting and Whiting (1975) called intimate societies, referring to the nature of the relationship between spouses. Our father-absent societies are the aloof societies of Whiting and Whiting and they correspond closely to societies with the "male supremacist complex" of Divale and Harris (Divale \& Harris, 1976; Whiting, 1965; Whiting $\&$ Whiting, 1975). The difference between these two types of society is a difference in male reproductive strategy, and the correlates that we and others have observed follow from this difference in strategy. In this section we outline some of these correlates and then discuss why males should follow one or the other of their strategy alternatives.

Biologists understand that diploid organisms commit a certain fraction of their resources to reproduction (as opposed to growth, maintenance, etc.) and that this reproductive effort can be partitioned into mating effort and parental effort (Kurland \& Gaulin, 1984). Mating effort is the expenditure of resources in obtaining access to a sexual partner, while parental effort is the expenditure of resources in parental care. Female mammals have high obligate parental effort compared 
to males, because of internal fertilization, internal gestation, and lactation. Male mammals, on the other hand, show more variability in reproductive effort, ranging from the domestic labor of the beaver to the belligerent mating battles of elephant seals.

This variability in male reproductive strategy has a close human counterpart. Human males can act like dads, working at provisioning the young of a mate or mates (but usually one), or else they can act like cads, and work at maximizing sexual access to a large number of mates (Dawkins, 1976). Of course, males are opportunistic and most males probably pursue some mixture of pure strategies that varies over the life course. Nevertheless, father-present societies are those where most males act like dads and father absent societies are those where most males act like cads.

Correlates of these two kinds of society are as follows:

- Father-absent societies are particularly prevalent in so-called middle-range societies, i.e., those where agriculture is practiced at a very low level of intensity and there is low human population density. The father-absent complex is also found among hunter-gatherers in rich stable environments like the American Northwest Coast and among the lowest socioeconomic groups in industrial cities (the "underclass": see Banfield, 1968). Father-present societies are more likely to be found among hunter-gatherers in harsher or less stable environments, among densely packed agricultural peoples ("peasants" Asian wet-rice cultivators), and in industrial societies ("working class" and those above).

- A marker of father-absent societies is that husbands and wives do not sleep and eat together, while in father-present societies they do (Whiting \& Whiting, 1975).

- Father-absent societies are associated with local raiding and warfare, while father-present societies are associated with external warfare or else imposed peace. The local raiding is often for purposes of capturing women.

- Public relations between men and women are hostile and antagonistic or else carefully avoided in father-absent societies, while relations are more relaxed and intimate in father-present societies.

- There are more likely to be high levels of male violence in father-absent societies, especially public, highly visible violence associated with male display by means of colorful costumes, ornaments, etc. Male style in this context has been labeled protest masculinity by some psychologists. This local-level violence may also be directed at women.

- Male public bombast, oratory, and rhetoric are more prevalent in father-absent societies. Speech and language are primary vehicles for male competition. 
- Bonding between males and females is more transient in father-absent societies, and the prevalence of polygyny is higher. Social forms of marriage may not reflect the underlying mating system.

- There is a pattern of abrupt termination of parental care in father-absent societies, characterized by intense nurturance by the mother followed by sudden cessation of maternal interest at (fairly early) weaning. Toddlers are then cared for by siblings and other children, fostered out to older female relatives, or both. This pattern is accompanied by high fertility and, often, high levels of weaning and toddler mortality (Harpending, Draper, \& Pennington, in press; Fonseca, 1986; LeVine, Correa, \& Tapia Uriba, 1986; Scheper-Hughes, 1985).

- When a women adopts this kind of mating style it has direct consequences for her maternal investment in offspring. A woman who provides domestic and sexual services for a man can expect some continuity in the relationship. However, a better "hold" on her man comes when she produces a child which he and others in the community recognize as his own (Fonseca, 1986; LeVine, et al., 1986; Oppong \& Bleek, 1983). This strategy, of course, contributes to high levels of fertility since offspring seem to be required for the maintenance of the union, however brief. The woman's new mate does not welcome the idea of supporting her offspring by previous unions; these she typically fosters out to her own or the children's father's kin. Thus, the pattern of low male investment and accompanying father absence goes hand in hand with reduced maternal investment per child. In natural fertility populations a woman usually keeps her child until it is weaned or through early childhood, when the entrance of a new boyfriend begins the cycle anew.

- In father-present societies male subsistence labor is high and directed toward provisioning of a mate and offspring. In this context females (or their families) who perceive early that male parental effort is important to their reproduction will be more careful and reticent at adolescence in forming sexual relationships and will form more stable pair bonds. In father-absent societies there is little direct provisioning of mate and offspring by males. Women often provide the majority of subsistence labor. These father-absent females recognize that male parental effort is not crucial to reproduction and they are less coy and reticent, engage in sexual activity earlier and with less discrimination, and form less stable pair bonds (Schneider, 1961; Draper \& Harpending, 1982).

- Women who mate with cad males recognize that they cannot be relied upon for substantial economic support or long-term commitment to the pair bond. Consequently, one finds in the literature describing father-absent societies that women devalue the male parental role and, where they are not constrained by restrictive mores, they form transient liaisons with various men. Women try to capture economic resources from their mates early in the sexual rela- 
tionship since they know that later the man will be either gone or improvident. Ideally we would at this point, specify why some cultures fall into the father-absent pattern and some into the fatherpresent pattern, but we do not have any clear and explicit theory. A clue is provided by the comparative study of mating systems in birds and animals: we should look at the fitness payoff to the male subsistence work versus the fitness payoff to male competition.

If there is abundant food, then a male does not benefit from provisioning his offspring to the extent that he does if food is scarce, so the payoff to male labor must be a crucial element in our theory. But "payoffs" are filtered through the human perceptual system, so that how resources are perceived is part of the corpus of culturally transmitted behavior of our species. What we can say is that competitive, fractious males are acting as if resources were plentiful regardless of our own objective evaluation of resource availability (Draper, in press).

It is not easy to discern cause and effect in the dynamics of this system. For example, the urban underclass in industrial cities fits our model of father-absent societies in many ways: there are decorative, belligerent, highly verbal males, matrifocal families not provisioned by a mate, high levels of fertility and (relatively) low-grade parental care, fostering, and adoption (Belsky \& Draper, 1987). But the underclass has fewer, not more resources, than other socioeconomic groups! It may be that the culturally transmitted perception of resource structure determines underclass membership: the so-called working class (Banfield, 1968), the economic neighbors of the underclass, is characterized by values and behavior that fit our father-present model. We need a meaningful model of the evolution of human perceptual strategies to sort all this out.

Elsewhere in the world the fit between more objective estimates of resource structures and our model seems better. Father-absent hunter-gatherers are found in rich ecosystems (Northern Australia, New Guinea, the Northwest Coast of North America) in comparison with father-present hunter-gatherers (!Kung Bushmen, Shoshone). And father-absent agricultural peoples are found at low densities where subsistence can be provided by female labor alone (Amazon basin swiddeners, the African "female farming systems" of Boserup, 1970), while father-present agriculturalists are characterized by higher densities and more labor-intensive agricultural practices (Asian wet-rice cultivators, European peasants).

We discuss this matter at greater length below when we consider the demographic transition in European history as a transition from a father-absent pattern to a father-present pattern.

\section{Social Science Data About Father Absence}

We think that data from the social sciences about the effects of being reared father-present versus father-absent represent a complex series 
of conditions which occur in early childhood and are an example of contextual variables which trigger reproductive outcomes which are not fully expressed until later in the child's life. Our analysis draws on the findings of psychologists and sociologists but differs in that it attempts to explain why the experience of being reared father-absent or father-present seems to produce the outcome. The following is a brief review of the findings from the father-absence literature.

\section{Father-Absent Boys}

It has been widely reported that boys reared in father-absent households are different from their peers reared in nuclear families. The actual behavioral contrasts between the two kinds of boys vary somewhat according to the cultural environment and according to whether father absence is nonnormative (as among middle-class people in Western societies) or whether it is normative (as in the case of some traditional, non-Western societies in which polygynous marriages, weak marital ties, and strong sex-segregating practices serve to isolate women and children from men).

\section{Father-Absent Boys: Nonnormative}

Boys reared in Western type societies by mothers and with little or no influence from fathers do more poorly in school, are less likely to have the analytic and mathematical skills common to boys, show less popularity with peers (Biller 1970; Lynn 1974), reject authority, particularly when it is imposed by adult females, and have a more aggressive behavioral style (Miller, 1958) sometimes interpreted as "overcompensation" for insecure masculine sex-role identification (Whiting, 1965). As they age they adopt attitudes that denigrate females and at adolescence they often develop a precocious sexual interest in girls, an interest which emphasizes sexual conquest of many girls rather than the establishment of more durable and intimate relations with one girl (Rohrer \& Edmunson, 1960).

Boys reared under Western, normative father-present conditions are less likely to exhibit these characteristics. When tests are available they are more likely to show the typical masculine pattern in which scores on tests of spatial and analytic ability are superior to test scores on verbal ability. Boys reared by investing fathers are not notably resistant to authority, have good relations with male peers, and have generally positive attitudes toward women. They are more likely to delay sexual experience, discriminate in their choice of females, and to have non-exploitative relations with women. 


\section{Father-Absent Boys: Normative}

For a reader not familiar with the structuring of marital relations in father-absent societies we provide a brief explanatory digression. In order to follow this discussion the reader needs to put aside his/her own preconceptions about what the terms father, fatherhood, and marriage imply. In societies in which fathers are emotionally and psychologically aloof from women and children there are, nevertheless, family roles which correspond formally to those of Western, nuclear families. That is, women marry men and conceive children by these men who are socially recognized as fathers to their children. Usually the fathers are also genitors of their children. However, prevailing customs regarding the division of labor and relations between the sexes are such that men and women, with their young children, have limited personal and social contact, even though the marriages that tie men and women may be durable. Many prestate, tribal-level societies are like this, as indicated in a previous discussion.

The outcomes for boys who are reared under conditions of normative father absence are not precisely comparable, particularly since formal schooling is often not available to provide comparable social contexts or opportunities to observe cognitive factors. However, many of the behaviors we see are the same even though there is nothing unusual about father absence in these societies. The following is a list of behaviors and practices characteristic of males in societies which we would class as normatively father-absent: High levels of aggression and competitive display among males, usually including much bombast and rhetoric and occasionally including outright physical violence; sexrole asymmetry, in which male dominance and female subordinance are pervasively established in secular and sacred spheres of social organization; and sex-role antagonism, by which we mean that men and women hold stereotypically negative and hostile attitudes toward the opposite sex (Schuster, 1979; Murphy \& Murphy, 1974; Meggitt, 1964; LeVine, 1959; LeVine \& LeVine 1966; Whiting \& Whiting, 1975).

\section{Girls}

Girls, regardless of father absence or presence, do not show a consistent pattern on cognitive tests. Instead, girls show verbal ability scores on standard tests which are typically superior to test scores of quantitative ability and especially spatial ability. Also, since girls are nearly always reared by adult females, they do not lack appropriate sex role models which enhance correct sex role identification. However, at adolescence some father-absent girls differ from controls in the domain of sexual behavior. Variables which have been studied include attitudes 
toward males and masculinity, interest in sexuality, timing of appearance of sexual interest, and interest in developing a stable relationship with one male.

\section{Father-Absent Girls: Nonnormative}

In general, father-absent girls show precocious sexual interest, negative attitudes toward masculinity and males, and poor ability to maintain sexual and emotional adjustment with one male (Bloss, 1969; Friedman, 1969; Hetherington, 1972; Rainwater, 1971).

Father-present girls at adolescence are unlikely to show the above constellation of traits. They are slower to acquire sexual experience, choosier in selection of boyfriends, and make what Western sociologists think of as correct and normal progress toward the formation of durable pair bonds.

The effect of being reared under conditions of father absence or presence apparently influences reproductive behavior including sexual expression, timing of sexual expression in individual ontogeny, and attitudes toward the opposite sex. The association between the contextual variable (household structure or mother's attitude toward men) and later behavior occurs with regularity and in a variety of cultural environments. It is apparently not the result of a fortuitous coincidence between modal family type and sexual mores across settings. For example, Hetherington (1972) reports that divorced mothers in her American lower-middle-class sample were shocked and dismayed by their daughter's "precocious" sexual interest. (See Barglow, Bernstein, Exum, Wright, \& Visotsky, 1968, for similar report.)

\section{Father-Absent Girls: Normative}

Interestingly enough, the sequelae of being reared father-absent in normative father-absent societies are not very visible, given the current state of ethnographic reporting on the behaviors of females. In traditional society, a young female is often married either at puberty or prepubertally (Whiting, Victoria, \& Burbank, 1986). In this case her sexual conduct is moot, since her sexual union is regularized and culturally approved. The young woman typically has married a man considerably older than she. As a bride she finds herself incorporated into the sex-segregated domestic life of other women who are related by marriage to her husband. These women may be her co-wives or the sisters or mother of her husband. Any sexual adventures she might be tempted to initiate will be inconvenienced by the vigilance of these other women, who have varying interests in the reproductive potential of a newly in-married woman. Co-wives already regard an additional wife as a drain on the single husband's ability to provide for multiple wife and offspring sets, and they can- 
not be expected to turn blind or benign eyes on their rival's infidelity. The mother-in-law has obvious reasons for keeping her daughter-inlaw in check: the older woman wants her son's children to be her own grandchildren (Dickemann, 1981).

In many traditional societies, then, females are unable to express what we posit to be the reproductive effects of their own father-absent rearing. Evidence for cross-sex antagonism is, however, not hard to find. (See Potash, 1978; Levine \& Levine, 1966; Stack, 1974). They marry early and their reproductive careers begin without controversy under the strictures of a sexual double standard in which females trade personal autonomy in return for the social and physical security which comes with the status of married women.

The fact that father-absent rearing in fact has robust effects on reproductive behavior is suggested by the current tendency toward unwed, teenage pregnancy both in low socioeconomic groups in complex societies and in Third World countries, for example sub-Saharan Africa. Various factors work to exacerbate the quandary. Falling menarcheal age, improved nutrition, and perhaps other public health practices result in a secular trend toward earlier age at first menstruation for girls. Even accounting for months or years of adolescent sterility, the effect is to move down in chronological age the risk of pregnancy (Lancaster, 1986).

As education becomes more widely available and prerequisite for jobs in the modernizing sector of the economy, women who previously may have married at 15 years of age delay marriage until their late teens or early twenties. Further, school-age girls associate with younger men, closer to age-mates, who are in a poor position to act as fathers and husbands when a pregnancy is begun. The same modernizing influences which have brought about improved public health, reduced epidemiological risk factors, formal schooling, and youthful migration to urban areas also impair the ability of elder kinsmen to control the sexual activity of adolescent girls (Kayongo-Male \& Onyango, 1984; Peil \& Sada, 1984; Obbo, 1980). The result is dramatically increased rates of childbearing among young women. The "problem" attains awesome proportions when one realizes that in some countries $50 \%$ of the population is under 15 years of age.

It should be stated that, except as declining menarcheal age extends the age range of individuals at risk, teenage pregnancy is not new or unnatural. What is new and unnatural is the lack of social provision for the consequences of youthful sexuality. In the very recent past nubile girls were quickly removed from the mating marketplace by senior males who attempted to control their sexual behavior in order to insure paternity. The male age-mates of the prized young females were forced into either celibacy or relatively infertile matings with older or unattached women. Young men whose sisters married early could expect to wait another 10 or 15 years before marrying. 
During the hiatus, many of these junior men were lost to migration, warfare, death, or morbidity in competition with other males, often over women (Dickemann, 1979).

\section{The Demographic Transition}

Anyone interested in the interface between evolutionary biology and human social behavior has to confront the last few centuries of demographic history of Euro-American industrial nations, the so-called demographic transition (Vining, 1986; Draper \& Harpending, 1987; Caldwell, 1977). This is the decline in both death rates and fertility rates in the eighteenth, nineteenth, and twentieth centuries, with the result today that in Western industrialized countries, large numbers of people, those with great access to resources necessary for survival and reproduction, voluntarily reduce the numbers of their offspring. This pattern is remarkable since one might expect humans, like any other species, to respond to an improved environment with increased fertility.

We refer specifically to industrial upper-, middle-, and workingclass families, who enjoy extremely favorable conditions in terms of health, food, political stability, and numerous "free" social services ranging from public education and public health services, to stable currency. But these groups have switched to the strategy of producing small numbers of "quality" offspring rather than larger numbers of "lower quality" offspring. "Quality" here refers to the amount of parental resources invested in each offspring, the consequent probabilities that offspring will survive to maturity, and the ability of offspring to compete with conspecifics through education, heritable wealth, land, etc.

The fertility decline is an empirical finding, but little is known about why it occurs. What perception on the part of fertile couples could bring about the behavior, and what proximate mechanisms could trigger the changed perceptions of the state of the environment leading to such a fundamental change in reproductive strategy? The answer is not as obvious as it might seem when one recalls that in the same complex, socially stratified postindustrial societies, different groups show different patterns of fertility. The most obvious difference is between the high fertility associated with the lowest socioeconomic groups and low fertility among the more affluent groups. What estimate of the state of current and/or future resources are people making, and with reference to what qualities of the environment are people arriving at these estimates? ${ }^{1}$

1 The Hutterites are an instructive example of an affluent social group in which fertility remains high by present-day world standards (Hosteller, 1974) 
Reflecting their assumption that the rest of the world will undergo the same change in demographic configuration, demographers refer to pretransition societies as those found today in many parts of the Third World, where populations exhibit extremely high fertility in the face of what by objective measures appear to be extremely limited resources. People in these societies have a reproductive strategy which emphasizes numbers rather than quality of offspring. High fertility persists with a falling but still significant mortality. The outcome is steadily increasing population size, putting staggering demands on national and local communities.

At the local level land, water, and access to markets become limited. At the national level shortages occur as governments are unable to satisfy demands for education, employment, public health, and economic development, which in turn could help the country absorb the growing and increasingly restive labor force. As we did above, we can ask about perceptions of environmental quality among people pursuing a high fertility strategy and about which proximal mechanisms trigger these perceptions. As many fail to appreciate, the fertility behavior of modern people is not without precedent. There are other populations living under very different kinds of socioeconomic organization who also show the "modern" pattern. These cases are extremely instructive for those of us who would hope to understand the influence of institutions on individual reproductive behavior.

Our current fertility pattern of low mortality and low fertility is not "new," for it has had a long run as the preferred human fertility pattern in prehistoric times (Cohen, 1980; Short, 1976; Lancaster \& Lancaster, 1983). Before the advent of agriculture and animal husbandry, world population was extremely low and increased at an extremely slow pace (Hassan, 1980). At this time the prevailing economy was nomadic hunting and gathering. Group size was small (probably between 50 and 100 individuals) and social differentiation was extremely limited, amounting in many cases to social divisions based essentially on no more than age and sex. Comparison of the patterns of marriage, fertility, and parenting behaviors at the two ends of the range of sociocultural complexity (hunter-gather and postindustrial society) reveals some surprising similarities. For example, there are in both groups low fertility, low mortality, monogamous marriages, high biparental investment in children, and prolonged, intimate and intense contact between parents and children (Briggs, 1970; Draper, 1976; Howell, 1979; Kaplan, Hill, \& Hurtado, 1984; Lancaster \& Lancaster, 1983).

The pretransition pattern (which we are arguing is a transient intermediate stage of cultural evolution) is characterized by a drastically different constellation of reproductive patterns: marriages are typically polygynous, or temporary, or both, norms stress pronatalism as a necessary antidote to high child mortality, parental investment per 
child is low, especially after infancy, and contact between children and their parents is less intense, intimate, and prolonged. Surrogate caretakers, often older children but also a series of foster parents, living in different communities provide the alternative care for children in pretransition societies.

We suggest that this variation in fertility behavior among different populations is itself a cue to the presence of evolved learning biases related to fertility behavior. In other words, humans share with some other animals an ability to regulate their reproduction, not only on the basis of present essential resources, such as food and freedom from stress, but also on the basis of cognitions about the long-term quality of the environment. For humans and other social species, the institutions that regulate kinship, mating, and subsistence are important shapers of the perceptual estimation of environmental quality.

What is the nature of the stimuli with which individual humans deal and what role can they play in the assessment of environmental quality by an individual? For humans, postnatal learning determines many of the options available. We suggest that a fruitful place to look for environmental stimuli that can influence the individual's estimation of environmental quality is the experiences individuals have in the early years of life. We focus on a restricted time period, namely, the toddler phase, but experiences before and after this developmental stage are presumably also influential. We argue that the postnatally perceived environment of the individual will vary according to the nature of the parenting practices which support that individual in his/her dependency. In their turn, the perceptions of environmental resources will influence the person's reproductive behavior at sexual maturity. The human postnatal environment is mediated through social institutions and technology. Some institutions will foster cognitions of adequacy or abundance in resources; other institutions may foster a cognition of scarcity of relevant resources.

Under ancient hominid conditions, a prominent part of the environment for parents and dependent offspring must have been each other. At that time, just as today, the young required years of prolonged care, and the mother herself was the one who delivered the bulk of the care. This kind of pattern is described for most contemporary hunter-gatherer groups. Because of the small size of the groups, the nomadism, and the lack of alternatives to mother's milk for nourishing young, the mother and her mate would have been the primary target of succorance requests by the child. This kind of child played a major and active role in sustaining a high level of parental investment. Even though other group members could assist the parents it would be unlikely that a system of substantial surrogate caretaking would develop. The parents, particularly the mother, were the significant caretakers of children under about 4 years of age. An especially important point for the argument we are developing is this: the mother could not elude her off- 
spring. The parents could abandon or neglect a child and in this way terminate investment. On the other hand, the parent could not readily delegate major caretaking responsibility to others in the first several years of the child's life. This child was in a position to regulate actively parental care.

\section{Parent Rearing}

As above when we argued that the effects of father absence reflect learning bias for sensitivity to mother's pair bond status, we propose that the child who is nurtured primarily by the parent(s) develops a distinctive set of cognitions about his/her environment. These cognitions contrast with those of a child who is reared by surrogate parents, or, especially, by a multiaged and variable group of peers.

The parent-reared child operates in a world populated by significant, powerful others whose size and status are markedly different from those of the child. The parents and their adult surrogates are few in number and relatively stable in composition. The child who must negotiate essential goods and services from the same, small number of powerful others (the parents) may conclude that goods are hard to obtain. Because of the status difference between parent and child, the child spends relatively little time in dominance struggle and competitive manipulation of other people. This child knows where resources can be obtained, and they are handed over increasingly as the child masters adult competence. This attribute is important because the child is not learning that desirable things are held by a loose congregation of others whose goodwill must be maintained by constant social attention. We predict that a consequence of this rearing environment is that it teaches the child an essentially conservative approach to the evaluation of apparent resources.

\section{Peer And Surrogate Rearing}

The social, emotional, and economic landscape traversed by children in many pretransition societies is different in major respects (Bledsoe \& Isiugo-Abanihe, in press; DuBois, 1944; Fonseca, 1986; Korbin, 1981; Murphy \& Murphy, 1974; Ritchie \& Ritchie, 1979; Scheper-Hughes, 1985; Scrimshaw, 1978; Weisner, 1987). One of the most detailed descriptions of this pattern is found in Polynesia. According to the Polynesian practice, when the child has passed the stage of infancy and requires less intensive care, it is not only turned loose for the daylight hours but is also actively discouraged from putting too many demands on the parents. The child is discouraged from hanging too close to its mother, and instead, is supposed to join a multiaged peer group. Often he/she is assigned to a particular older child who provides much 
of the care previously provided by the parent: feeding, dressing, disciplining, protecting. The peer group is changeable in size and composition but we argue that the characteristics of peers as socializers have implications for the cognitions that the child forms about the quality of environmental resources.

We reason that children who are reared in this context learn that resources can come from a variety of persons depending upon how good the child's access to individuals in his peer network is. This kind of child garners resources in proportion to his ability to manipulate social relations; social skills are acquired early and are important adjuncts for survival. Peer group rearing may foster an outlook in an individual who sees, regardless of objective perceptual reality, a host of potential resources based on culturally acquired evaluations and attitudes. The child reared by a parent is freed from this kind of social work and learning since his/her social skills don't pay off in food and resources the way they do in a peer group context.

In the system of peer rearing a parent is protected from attempts by the child to elicit resources, because the mother deflects onto others many of the demands posed by the child. To the extent, then, that the child's presence and physical demands on the mother constitute a significant element in her cognitions about resource adequacy, the mother whose child is segregated in this way is less inhibited by the demands of one child from conceiving another.

Parent-reared children such as those found among foragers and some horticultural groups and among relatively affluent socioeconomic classes in modern society are similar in that they have direct access to adult sponsors, usually their parents. The parent who provides for a child under these circumstances deals with a different kind of offspring - one who does not go away and who creates many and continuous demands on the parent. This condition of high offspring salience may lead to a changed cognition on the part of the parent regarding the child's "needs." Of course, objectively, children all need about the same things for basic survival. Under conditions of peer care these needs are met differently and by different people. The outcome can be satisfactory. However, the singular feature of the parent caretaker system is that the child's needs are being met by the parents; they are the focus of the child's attention and are recipients of the child's requests. The stimulus value of offspring in this situation is different. As a result, the cognitions on the part of the parents are changed regarding how to deal with children and how to provide for them.

Our model with respect to the topic of peer versus parent rearing is in many ways analogous to the model detailed in the discussion of the effects of father absence. In both cases we argue that children are differentially sensitive to certain components of their social context as a result of evolutionarily programmed learning biases. In 
the father-absence case, children are sensitive to mother's pair-bond status and their reproductive strategies are canalized. In the parent versus peer rearing case, children are sensitive to the characteristics of the personnel who provide proximal care in the late infancy/early childhood phase. Depending on the type of care received individuals are likely to pursue a quality offspring versus quantity offspring parenting style. An advantage of our formulations, which are admittedly unorthodox, is that they attempt to specify the proximal mechanisms whereby individual behavior is shaped and they state in fitness terms why the proximal mechanisms and stimuli produce the outcomes they do.

We believe the inferences regarding interactions between institutions, proximal mechanisms, and learning bias are reasonable given the relatively limited constraints under which human reproduction and child socialization have operated in our evolutionary past. Under all known social conditions women and men establish sexual relationships of greater or lesser durability and conceive children. Depending upon the physical resources and the social conditions women may or may not require the active help of their mates in order to rear their offspring to maturity. When they do, women make sexual concessions to their mates primarily to assure paternity certainty. This "contract" generally insures that the father is salient to her and her children both because of his active presence in their domestic life and/or because the mother signals his worth to her offspring.

In the opposite case, when women do not require the help of their mates to rear offspring, they make limited or no sexual concessions to their mates, paternity is uncertain, and male salience in the domestic setting is correspondingly muted and devalued by the mother. We argue that the household structure has the predictable outcomes for children's reproductive behavior at maturity because of a learning bias favored by evolution. Children who "draw the right conclusions" from their mother's unpaired status have improved fitness in the type of social environment with which the mother is familiar (or the mother has prepared for them). Children do not invest time seeking durable and monogamous marriage partners. Indeed, time spent in this way would be wasted.

Children who draw the right conclusions from the mother's paired status are likewise headed for a fitness maximizing reproductive strategy in the alternative type of social environment prepared for them by their mothers (and fathers).

We suggest that the consequences of parent versus peer rearing are significant primarily in terms of what they convey about the adequacy of resources. Individuals who are reared by parents perceive resource scarcity and "hand rear" their offspring, a decision which both reduces fertility naturally and makes adults more amenable to artificial means 
of birth control when they are known. Individuals reared by a series of parental surrogates conclude that critical resources will be forthcoming from within the social network. They perceive no "emic" scarcity, although by "etic" accounts the demographic reserves are depleted.

A further advantage of our unorthodox propositions is that they allow us to explain and predict the variability in individual behavior that occurs in apparently the same social or cultural context. As we stated above in our discussion of easy and hard learning, one can predict that with respect to behaviors as central to fitness as sexuality, mating, and parenting, the individual is best served by natural selection if he/she can learn readily certain behaviors or the potential for certain behaviors. The mother herself and the system of social support are, from the child's point of view, the most infallible sources of information about resources, survival, reproduction, and mating.

Many years ago Freud asserted that what is learned early is learned best. We would agree with this but we would explain it differently. Cognitions acquired from learning bias and rearing effects are probably quite resistant to change. If this is so we would predict that the youth of low-income ghettos of modern stratified societies will not readily trade their "birth rights" for the secular inducements dangled by majority politicians. Nor will adults in Third World societies "see" the rationality of having fewer children as a route to a better life. Their evaluations of resource availability and the quality of life are based on a different and prior set of perceptions (Bulato \& Lee, 1983). It is probably true that big changes in the behavior of large numbers of people will come about when certain key, contextual features of the experience of both men and women are changed in early life. Contemporary programs to bring about large-scale changes in reproductive behavior of adults are probably handicapped by this phenomenon of lag between individual psychologies and an objective determination of resource availability.

\section{Criminality and Hysteria}

We have been discussing how humans ought to learn about their social environment and how this learning ought to direct their further learning, other aspects of their development, and their behavior. We have also discussed the ways that evolutionary theory and data make sense together, even though people are not necessarily consciously aware of the meaning that biologists would ascribe to the choices that they make. But not all the interesting insights from evolutionary biology are about learning.

In this section we will discuss the characteristics of people who don't follow the same rules as most of the rest of us-sociopaths and hysterics. We will describe the most clear-cut manifestations of these 
traits, but we must keep in mind that they are almost certainly quantitative traits and that there are few "pure" cases. Being a sociopath is like being tall: everyone is a little bit tall, and some people are taller than others. Sociopathy and hysteria are also like stature in that most of the differences among individuals seem to be due to gene differences. We will not go over the evidence here, but there is no indication that any kind of learning is involved in the genesis of these traits, as there is with the traits associated with father absence. However, social systems differ in the extent to which they are congenial to or inimical to the spread of sociopathic individuals in a population.

Psychiatrists have a diagnostic category of sociopathy or antisocial personality disorder. There is a very big overlap between the psychiatrists' sociopaths and what police and the courts see as habitual repeat criminals. When one looks carefully at the list of characteristics of sociopaths, it is apparent that criminality is only one of a number of traits that most of these males share. We must make sense of a whole constellation of traits if we are to understand sociopathy. Further, it is not clear that it really is a disorder. The whole idea of disorder or pathology is, of course, bound to the perspective of whoever is doing the evaluation. Sociopathy is certainly a disorder from the viewpoint of the courts and the police, but it may not be a disorder from the perspective of Darwinian fitness.

Other intriguing associations are to be found in the literature on sociopathy. Female relatives of sociopaths are at risk of showing many of the same traits as the males, but they are at much lower risk. But many of these females exhibit another psychiatric disorder, called hysteria or Briquet's syndrome, and we have to explain why females in these families should have a quite different set of symptoms from the men.

First, let us look at the data, that is, the characteristics that mark sociopaths and hysterics. Sociopaths are (usually) males with histories of criminality, absence or low levels of apparent "conscience," lack of long-term interpersonal bonds, verbal facility and quickness, charm, mobility, and vagrancy, promiscuity, illegitimate offspring, and abandonment of spouse and children (Cloninger, 1978; Goodwin \& Guze, 1984). Notice that some of these characteristics are, at least theoretically, objective and measurable like numbers of illegitimate offspring. Others are anecdotal, like charm and verbal facility. We think that the criminality is incidental here, and that the core characteristics (i.e., the characteristics that have been the focus of selection) are the mobility, the promiscuity, and the abandoned mates and illegitimate and abandoned offspring.

The way that sociopathy and socioeconomic status interact confounds our interpretation of data here. One view is that sociopathy is much more prevalent in lower socioeconomic groups (Cloninger, 1978), but another is that low-SES sociopaths are much more likely to 
commit crimes for which they are arrested and jailed. Middle- and upper-income sociopaths, according to the latter model, express the trait in ways that are less visible to the judicial and penal systems.

Briquet's syndrome (Goodwin \& Guze, 1984) is a diagnostically distinct trait, almost always found in females, characterized by multiple complaints (specifically medical complaints in the medical literature), attention-seeking, sexual difficulties, promiscuity, and illegitimate offspring. It seems to be the expression in females of the same genetic material that leads to sociopathy in males (Cloninger \& Guze, 1970), as if male-female differences were the result of sex differences in development of the brain (Goy \& McEwen, 1980). The medical model of an hysteric female is one who suffers from multiple medical complaints, none of which correspond to anything objectively ascertainable on other grounds. These medical-hysteric females undergo "unnecessary surgery" and in other ways take of the time and attention of medical practitioners. But if, as we propose, the fundamental trait is selfdramatization and the exaggeration of need to males, then there may be females who act out the same kinds of interactions with clergyman, lawyers, politicians, etc. These would not appear in the medical literature because they would not come to the attention of physicians.

\section{The View From Social Theory}

We are all enmeshed in complex networks of social reciprocity and exchange. Some of these are very public, like traffic laws, while others are private within a very small group of people. It is as true of very technologically primitive societies as it is in complex societies like ours that individual success, reproductive or other, is highly dependent on the individual's ability to manipulate and use networks of reciprocity and exchange. Different individuals, we might expect, would bring different strategies to their interactions in these networks. To pick a likely dimension, some might be more reliable reciprocators and more likely to follow the rules (implicit or explicit). The advantage of such a "nice" strategy is that it will lead to reliable high returns if practiced in a network of other nice actors and that there is little cost (in the currencies of time, energy, and risk) expended on trying to come away with a better payoff from an exchange than others have gotten. But the line between compliance and gullibility is thin, and nice strategists generally fare poorly in interactions with those not so nice.

A fundamentally different set of proclivities in social exchange, the "sharp" strategy, would consist of generally trying to outdo other participants. Those who practice the sharp strategy may ordinarily outcompete nice strategists, but they incur the costs associated with manipulating the set of social rules and expectations. Sharp strategists would prosper, we expect, when social interactions with others were 
short-lived, since over time social partners would be ever better able to detect sharp strategists and avoid or constrain them. If it were possible to assess this hypothetical attribute of people, we would expect individuals to fall along a smooth spectrum from "nice" to "sharp" to "cheater" at the extreme. It is easy to see that both extremes would fare poorly in evolution: individuals who were too "nice," who did not withdraw from exchanges where they lost, would lose in competition with those who were more discerning. Similarly, extreme cheats would find few social partners and would do equally badly.

Since we have no instrument to measure the social reciprocity proclivity of individuals, we may ask what characteristics we would expect to see in people at various points along our hypothetical spectrum. Could we make interesting or nonobvious predictions from our sketchy theory? Does our theory help us understand anything about the world that we didn't understand before?

Let us concentrate on the "cheater" end of our continuum of proclivities. What would a human who was prone to cheat in social relationships be like? A number of predictions are immediate:

- The most obvious prediction is that there would be no easily perceptible markers of cheaters. A cheater who advertised his or her strategy wouldn't have much of a chance of success, so we expect from the start that the traits that we seek will be subtle.

- Given the constraints of subtlety, our hypothetical cheater would be charming, outgoing, and sensitive, at least outwardly. In other words, we expect our cheater to be skilled at interpersonal manipulation.

- Since the fitness of cheating decreases in proportion to the time his or her partners have to assess his reliability in reciprocation, good cheaters would be mobile. The longer they stay in one place, the lower their success. They should move frequently or, if in dense habitats like cities, they should change their set of acquaintances frequently.

- Since most of our skills, social and otherwise, are based on years of practice and development, we expect that cheaters would practice even when there was no immediate payoff to their behavior. For example, if cheaters needed to be very skilled at telling lies, then they should practice lying even when there is no good reason. The imperative to practice may account for the seeming maladaptive behavior of individuals like those evaluated by others as "habitual liars"

- Males and females should show fundamentally different manifestations of the underlying proclivity to cheat because the constraints on successful reproduction are very different for the two sexes. Females must expend a lot of time, energy, and risk in pregnancy and lactation, while males are under no such constraint. During most of human evolution female reproduction was constrained by the necessity to obtain food, while male reproduction was constrained by 
the necessity to obtain sexual access to females. (These statements are true of mammals in general, because high parental effort is engineered into mammalian females with their internal gestation and lactation.)

* Male cheaters should cheat, in the reproductive domain, on provisioning females after copulation or impregnation, that is to say they should be promiscuous and they should abandon offspring. In pursuit of this, we expect them to be especially skilled at seduction and at deceiving females about their potential to provide resources.

* Female cheaters, on the other hand, have less to gain by seduction of males and abandonment of offspring unless surrogate caretakers are available. But female cheaters are expected to be skilled at exaggerating their needs to males and at persuading males to provide resources to them. If their fundamental orientation is to extracting resources from males, as opposed to cooperative provisioning and rearing of offspring with a mate, then occasional calculated seduction and promiscuity might further this orientation.

We now suggest that the complex of sociopathy and hysteria makes a great deal of sense of data that are otherwise puzzling. For example, the literature on penology often mentions the charm of criminals (Ballesteros, 1979). Why should criminals be charming? The evolutionary approach suggests that some criminals are just sociopaths who got caught, that the criminality was a manifestation of their underlying generalized indifference to social rules, and that the charm is an integral part of their adaptation. Sociopaths also move around a great deal in their lives (Robins, 1971). The evolutionary approach predicts that male mobility would be one of the core characteristics of cheat strategists.

Perhaps the most striking lead provided by this view of the material is the way it helps us understand hysterics, since the association between hysteria in females and sociopathy in males makes no good sense otherwise. The insight that they are exploiting males rather than bonding with them explains why they simultaneously (1) are often frigid and profess a distaste for sex, (2) are often promiscuous, and (3) have disproportionate numbers of illegitimate offspring.

There are many immediate predictions about sociopaths and hysterics that proceed from this theory. For example, we would predict that hysterics would abandon their children to kin or to adoption agencies at high rates, that they would be much more willing to mate with males who possessed wealth (as opposed to younger males with longterm good prospects for future resource accrual ability), and that they would respond to female clinicians in a fundamentally different way than they do to males. In particular, many of their symptoms should disappear. There is anecdotal evidence of this, but we have not located any serious data on the matter. 


\section{Conclusion}

For many years the social and behavioral sciences have been dominated by the strong cultural paradigm which postulates that human social behavior is guided by learning and that humans can and do learn almost anything with equal facility. This paradigm acknowledged only the most pressing and obvious constraints of biology, like the need for food and water, the need for internal gestation, and the like.

A profound reevaluation has been occurring since the late 1960s, with mixed results so far. The new viewpoint emphasizes the power of our past and stresses the need to comprehend our evolved abilities, propensities, and biases in social and psychological theory. At the level of the individual the new viewpoint emphasizes evolved characteristics of the organism, while at the level of society it emphasizes the synthesis of social forms from the interactions of individuals as opposed to the older idea that social forms have to be analyzed on their own level. In particular, the new viewpoint accommodates individual selfishness, inequality among individuals, and institutionalized deceit and manipulation.

Much of the change in viewpoint involves no more or less than the relabeling of familiar phenomena. For example, we are today as likely to speak of "gullibility" as "compliance" in discussing the behavior of children. Similarly the "terrible twos" have been occasionally relabeled as "parent-offspring conflict." This change in labels is useful only insofar as it reflects a paradigm that allows us to understand individual and social phenomena that we did not previously understand, and, most important, a paradigm that allows us to predict things that we did not already know. The true proving ground of a scientific theory is not its ability to explain but to generate hypotheses which can be subjected to real tests. We emphasize this point of view here, even though in this chapter we have concentrated on a narrative account of one subset of the new viewpoint. The real work is generating and testing new hypotheses.

Our particular theme has been variation in reproductive behavior and the ramifications of this variation for other aspects of social life. We outlined two proposed learning mechanisms, or learning rules. The first was a rule about the nature of the parental bond, perceptions of this bond by the child, and subsequent tracking of learning preferences on the part of the child. Our theory is perhaps better able to accommodate extant data about father absence than are competing theories (see Blain \& Barkow, this vol., Chap. 13), but much empirical work remains to be done.

We then proposed another learning rule concerning the nature of provisioning of toddlers and the subsequent development of the toddler. Toddlers in peer-rearing societies obtain resources from a network of other children, and their fitness depends (and has depended 
in our evolutionary past) on their ability to manipulate social relationships. Since social networks are in effect the critical resources of peerreared children, we propose that social and other learning during development is profoundly affected by the difference between this and biparental rearing. In particular, we suggest that biparental rearing fosters a concern with the environment rather than with people and a very conservative perception of the adequacy of the resource stream.

Finally, we discussed sociopathy and hysteria as heritable differences in reproductive strategy, emphasizing the difference between fitness consequences of these behaviors (i.e., that they are adaptations) and social and moral consequences of these behaviors (i.e., that they cause damage to many of us.) Our theory is falsifiable, since it does generate predictions that could easily be tested in field studies. Many theories and explanations in social science do not generate new predictions and are impossible to confirm or deny.

\section{References}

Ahrens, R. (1954). Beitrag zur Entwicklund des Physiognomie und Mimikerkennens, tiel 1,11. Zeitschrift fur Experimentelle und Angewandte Psychologic, 2, 412-454,599-633.

Alexander, R. (1979). Darwinism and human affairs. Seattle: University of Washington Press.

Altmann, J. (1980). Baboon mothers and infants. Cambridge, MA: Harvard University Press.

Baker, S. W., \& Ehrhardt, A. A. (1974). Prenatal androgens, intelligence, and cognitive sex differences. In R. C. Friedman, R. M. Richard, \& R. L. Vande Wiele (Eds.), Sex differences in behavior. New York: Wiley.

Ballesteros, O. (1979). Behind jail bars. New York: Philosophical Library.

Banfield, E. (1968). The unheavenly city. Boston: Little Brown.

Barglow, P., Bornstein, M., Exum, D., Wright, M., \& Visotsky, H. (1968). Some psychiatric aspects of illegitimate pregnancy in early adolescence. American Journal of Orthopsychiatry, 38, 672-687.

Barkow, J. H., \& Burley, N. (1980). Human fertility, evolutionary biology, and the demographic transition. Ethology and Sociobiology, 1, 163-180.

Belsky, J. \& Draper, P. (1987). Adolescent parenthood, reproductive strategy, and prevention. Transaction/Society, (In press).

Biller, H. (1970). Father absence and the personality development of the male child. Developmental Psychology, 2, 181-201.

Bledsoe, C., \& Isiugo-Abanihe, U. (in press). Strategies of child fosterage among Mende grannies in Sierra Leone. In R. Lesthaeghe (Ed.), African reproduction and social organization. Oxford: Oxford University Press.

Bloss, P. (1969). Three typical constellations in female delinquency. In O. Pollak \& A. Friedman (Eds.), Family dynamics and female sexual delinquency. Palo Alto: Science and Behavior Books.

Boserup, E. (1970). Women's role in economic development. London: Allen and Unwin. 
Bowlby, J. (1969). Attachment. New York: Basic Books.

Bowlby, J. (1973). Separation and loss. New York: Basic Books.

Boyd, R., \& Richerson, P. J. (1985). Culture and the evolutionary process. Chicago: University of Chicago Press.

Briggs, J. (1970). Never in anger: Portrait of an Eskimo family. Cambridge, MA: Harvard University Press.

Bulato, R. A., \& Lee, R. D. (Eds.). (1983). Determinants of fertility in developing countries (Vols. I \& II). New York: Academic Press.

Caldwell, J. (1977). The economic rationality of high fertility: An investigation illustrated with Nigerian survey data. Population Studies, 31, 5-27.

Cavalli-Sforza, L. (1974). The role of plasticity in biological and cultural evolution. Annual of the New York Academy of Science, 231, 43-59.

Chagnon, N. A. \& Irons, W., (Eds.), (1979). Evolutionary biology and human social behavior: An anthropological perspective. North Scituate, MA: Duxbury.

Cloninger, C. (1978, August). The antisocial personality. Hospital Practice, pp. 97-104.

Cloninger, C., \& Guze, S. (1970). Psychiatric illness and female criminality: The role of sociopathy and hysteria in the antisocial woman. American Journal of Psychiatry, 127, 79-87.

Cohen, M. N. (1980). Speculations on the evolution of density measurement and population regulation in Homo sapiens. In. M. N. Cohen, R. S. Malpass, \& H. Klein (Eds.), Biosocial mechanisms of population regulation. New Haven, CT: Yale University Press.

Dawkins, R. (1976). The selfish gene. London: Oxford University Press.

Dickemann, M. (1979). Female infanticide, reproductive strategies, and social stratification: A preliminary model. In N. A. Chagnon \& W. Irons (Eds.), Evolutionary biology and human social behavior: An anthropological perspective. North Scituate, MA: Duxbury.

Dickemann, M. (1981). Paternal confidence and dowry competition: A biocultural analysis of purdah. In R. D. Alexander \& D. W. Tinkle (Eds.), Natural selection and human social behavior: Recent research and new theory. Oxford: Chiron Press.

Divale, W. \& Harris, M. (1976). Population, warfare, and the male supremacist complex. American Anthropologist, 78, 521-538.

Draper, P. (1976). Social and economic constraints on !Kung childhood. In R. B. Lee \& I. DeVore (Eds.), Kalahari hunter-gatherers. Cambridge, MA: Harvard University Press.

Draper, P. (in press). African marriage systems: An evolutionary perspective. Ethology and Sociobiology.

Draper, P., \& Harpending, H. (1982). Father absence and reproductive strategy: An evolutionary perspective. Journal of Anthropology Research, 38, 255-273.

Draper, P. \& Harpending, H. (1987). Parent investment and the child's environment. In J. Lancaster et al. (Eds.), Biosocial perspectives on human parenting. New York: Aldine de Gruyter.

Dublin, H. (1983). Cooperation and competition among female African elephants. In S. K. Wasser (Ed.), Social behavior of female vertebrates. New York: Academic Press. 
Dubois, C. (1944). The people of Alor: A socio-psychological study of an East Indian island. Minneapolis: University of Minnesota Press.

Durham, W. (1976). The adaptive significance of human reproductive behavior. Human Ecology, 4(2), 89-121.

Ehrhardt, A. A. \& Baker, S.W. (1974). Fetal androgens, human CNS differentiation, and behavior sex differences. In E. G. Friedman, R. M. Richard, \& R. L. Vande Wiele (Eds.), Sex differences in behavior. New York: Wiley.

Emien, S. T. \& Oring, L. W. (1977). Ecology, sexual selection, and the evolution of mating systems. Science, 197(4300), 215-223.

Fonseca, C. (1986). Orphanages, foundlings, and foster mothers: The system of child circulation in a Brazilian squatter settlement. Anthropology Quarterly, 59, 15-27.

Freedman, D. G. (1974). Human infancy: An evolutionary perspective. Hillsdale, NJ: Lawrence Erlbaum Associates.

Friedman, S. T. (1969). Relation of parental attitudes toward child rearing and patterns of social behavior in middle childhood. Psychology Reports, 24, 575-579.

Goodwin, D., \& Guze, S. (1984). Psychiatric diagnosis (3rd ed.). New York: Oxford University Press.

Garcia, J., McGown, B., \& Green, K. (1972). Biological constraints on conditioning. In A. Black \& W. Prokasy (Eds.), Classical conditioning: Vol. 2. Current research and theory. New York: Appleton-Century-Crofts.

Harpending, H., Draper, P., \& Pennington, R. (in press). Cultural evolution, parental care, and mortality. In A. Swedlund \& G. Armelagos (Eds.), Health and disease in transitional societies. South Hadley, MA: Bergin and Garvey.

Goy, R., \& McEwen, B. S. (1980). Sexual differentiation of the brain. Cambridge, MA: MIT Press.

Hassan, F. (1980). The growth and regulation of human population in prehistoric times. In M. N. Cohen, R. S. Malpass, \& H. Klein (Eds.), Biosocial mechanisms of population regulation. New Haven, CT: Yale University Press.

Hetherington, E. M. (1972). Effects of father absence on personality development in adolescent daughters. Developmental Psychology, 7, 313-326.

Hosteller, J. A. (1974). Hutterite society. Baltimore: Johns Hopkins University Press.

Howell, N. (1979). The demography of the Dobe !Kung. New York: Academic Press.

Kaplan, H., Hill, K., \& Hurtado, A. (1984). Food sharing among the Ache hunger gatherers of eastern Paraguay. Current Anthropology, 25, 113-115.

Kayongo-Male, D., \& Onyango, P. (1984). The sociology of the African family. London: Longman.

Korbin, J. E. (Ed.). (1981). Child abuse and neglect: Cross-cultural perspectives. Berkeley: University of California Press.

Konner, M. J. (1982). The tangled wing: Biological constraints on the human spirit. New York: Harper and Row.

Kurland, J. (1979). Paternity, mother's brother, and human sociality. In N. Chagnon \& W. Irons (Eds.), Evolutionary biology and human social behavior. North Scituate, MA: Duxbury Press. 
Kurland, J., \& Gaulin, S. J. C. (1984). The evolution of male parental investment: Effects of genetic relatedness and feeding ecology on the allocation of reproductive effort. In D. M. Taub (Ed.), Primate paternalism. New York: Van Nostrand Reinhold.

Lancaster, J. B. (1986). Human adolescence and reproduction: An evolutionary perspective. In J. B. Lancaster \& B. A. Hamburg, (Eds.), School-age pregnancy and parenthood: Biosocial dimensions. New York: Aldine de Gruyter.

Lancaster, J., \& Lancaster, C. (1983). Parental investment: The hominid adaptation. In D. J. Ortner (Ed.), How humans adapt: A biocultural odyssey. Washington, DC: Smithsonian Institution Press.

LeVine, R. A. (1959). Gusii sex offenses: A study in social control. American Anthropologist, 61(6), 965-990.

LeVine, R., \& LeVine, B. (1966), Nyansongo: A Gusii community. New York: Wiley.

LeVine, S. E., Correa, C. S., \& Tapia Uribe, F. Medardo (1986). The marital morality of Mexican women: An urban study. Journal of Anthropology Research, 42(2), 183-202.

Lumsden, C., \& Wilson, E. O. (1981). Genes, mind, and culture. Cambridge, MA: Harvard University Press.

Lynn, D. B. (1974). The father: His role in child development. Monterey, CA: Brooks and Cole.

MacDonald, K. (1984). An ethological-social learning theory of the development of altruism: Implication for human sociobiology. Ethology and Sociobiology, 5, 97-109.

Meggitt, M. (1964). Male-female relationships in the highlands of New Guinea. American Anthropologist, 66, 204-224.

Miller, W. B. (1958). Lower class culture as a generating milieu of gang delinquency. Journal of Social Issues, 14, 5-19.

Murphy, Y. \& Murphy, R. (1974). Women of the forest. New York: Columbia University Press.

Obbo, C. (1980). African women: Their struggle for economic independence. London: Zed Press.

Oppong, C. \& Bleek, W. (1982). Economic models and having children: Some evidence from Kwahu, Ghana. Africa, 52(4), 15-33.

Packer, C., \& Pusey, A. E. (1984). Infanticide in Carnivores. In G. Hausfater \& S. B. Hrdy (Eds.), Infanticide: Comparative and evolutionary perspectives. New York: Aldine.

Peil, M. \& Sada, P. O. (1984). African urban society. Chichester: John Wiley and Sons.

Potash, B. (1978). Some aspects of marital stability in rural Luo community. Africa, 48, 380-397.

Rainwater, L. (1971). Marital sexuality in four "cultures of poverty." In D. S. Marshall \& R. C. Suggs (Eds.), Human sexual behavior: Variation in the ethnographic spectrum. New York: Basic Books.

Ritchie, J., \& Ritchie, J. (1970). Child rearing patterns in New Zealand. Wellington: A.H. and AW. Reed.

Robins, L. N. (1971). Deviant children grown up. Baltimore: Williams and Wilkins. 
Rohrer, J., \& Edmonson, N. (1960). The Eight Generation. New York: Harper.

Schuster, I. M. G. (1979). New women of Lusaka. Palo Alto, CA: Mayfield.

Scheper-Hughes, N. (1985). Culture, scarcity, and maternal thinking: Maternal detachment and infant survival in a Brazilian shantytown. Ethos, 13, 291-317.

Schneider, D. M. (1961). The distinctive features of matrilineal descent groups. In D. M. Schneider \& K. Gough (Eds.), Matrilineal kinship. Berkeley: University of California Press.

Scrimshaw, S. C. M. (1978). Infant mortality and behavior in the regulation of family size. Population and Development Review, 4, 383-403.

Short, R. V. (1976). The evolution of human reproduction. Proceedings of the Royal Society (ser. B), 195, 3-24.

Silk, J. B. \& Boyd, R. (1983). Cooperation, competition, and mate choice in matrilineal macaque groups. In S. K. Wasser (Ed.), Social behavior of female vertebrates. New York: Academic Press.

Stack, C. B. (1974). All our kin: Strategies for survival in a black community. New York: Harper and Row.

Trivers, R. L. (1974). Parent-offspring conflict. American Zoologist, 14, 249-265.

van den Berghe, P. (1979). Human family systems: An evolutionary view. New York: Elsevier Science Publishing Co.

Verner, J. (1964). Evolution of polygamy in the long-billed marsh wren. Evolution, 18, 252-261.

Vining, D. R. (1986). Social versus reproductive success: The central theoretical problem of human sociobiology. Behavioral and Brain Sciences, 9, 167-216.

Weatherhead, P. J., \& Robertson, R. J. (1979). Offspring quality and the polygyny threshold: "The sexy son hypothesis" 113(2), 201-209.

Weisner, T. (1987). Socialization for parenthood in sibling caretaking societies. In J. Lancaster, J. Altmann, A. Rossi, \& L. R. Sherrod (Eds.), Parenting across the lifespan: Biosocial dimensions. New York: Aldine de Gruyter.

Whiting, B. (1965). Sex identity conflict and physical violence: A comparative study. American Anthropologist, 67, 123-140.

Whiting, J. W. M., \& Whiting, B. (1975). Aloofness and intimacy of husbands and wives: A cross-cultural study. Ethos, 3, 183-207.

Whiting, J. W. M., Burbank, V. K., \& Ratner, M. S. (1986). The duration of maidenhood across cultures. In J. B. Lancaster \& B. A. Hamburg (Eds.), School-age pregnancy and parenthood: Biosocial dimensions. New York: A1dine de Gruyter.

Wrangham, R. (1980). An ecological model of female-bonded primate groups. Behavior, 75, 262-300. 